\title{
Epidemiology of Scapula Fracture at a Level 1 Trauma Center in North India: A Pilot Study
}

\author{
Deepak Kumar ${ }^{1}$, Karan Gupta ${ }^{2}$, Devendra K Chouhan ${ }^{3}$, Mandeep Singh Dhillon ${ }^{4}$
}

\begin{abstract}
Aim: We did this study as a pilot project to plan the future research work in the field, with the aim to study the incidence and epidemiology of scapular fractures. Results of the study would be helpful in identifying the mass impact of the injury to the trauma victim and laying down the training curriculum.

Materials and methods: It was a cross-sectional study from July 1, 2018, to December 31, 2018; all patients presented to our level 1 trauma center with polytrauma and shoulder injuries were screened for fracture of the scapula. The demographic details, mode and mechanism of injury, associated injury, severity, and fracture pattern of all patients with scapula fracture were recorded. Patients were evaluated for concomitant injuries. Results: Out of total 1,730 patients presenting to the Advanced Trauma Center, PGIMER, Chandigarh, between July 2018 and December 2018 , $44(2.3 \%)$ patients were diagnosed with scapular fractures. Total $63.4 \%(28)$ of patients sustained various associated injuries.

Clinical significance: Results of this study have raised the awareness that fractures of the scapula are on the rise compared to what was thought previously.

Conclusion: Our study mandates the need of more dedicated screening methodology at the busy trauma center, which could reduce the chances of missed scapular fracture. Moreover, we could be able to identify more frequent fracture patterns and area of research specific to our setting. Keywords: Age distribution, CT diagnostics, Epidemiology, Incidence, Scapula fracture, Shoulder girdle injury, Trauma centers.

Journal of Postgraduate Medicine, Education and Research (2021): 10.5005/jp-journals-10028-1409
\end{abstract}

\section{BACKGROUND}

Scapula fractures are relatively uncommon injuries observed in the trauma patients, constituting for 3-5\% of shoulder girdle injuries. ${ }^{1,2}$ Fractures involving the body of the scapula are more common and result from a direct high-energy blunt force, whereas both glenoid and scapular neck fractures happen because of the indirect force transferred by impaction of the humeral head into the glenoid fossa. ${ }^{3-5}$ However, most of the scapular fracture does not require any surgical intervention while there is need for severely displaced fractures. Inadequate management of such fractures can result in malunion and subsequent poor shoulder function as a consequence to rotator cuff dysfunction, scapula-thoracic dyskinesis, and impingement. $^{6-9}$

Initially in developing countries, the timely diagnosis and inadequate management was the primary concern among scapula fracture patients. However, as a consequence of the increasing rate of the road traffic accident (RTA), increased awareness, and advanced imaging techniques, the reported incidence of the scapula fractures is showing the rising trend, which has attracted more research in this field.

India is one of the developing countries with a remarkably high rate of RTA, with 464,910 RTAs registered in 2017, claiming 147,913 lives and causing injuries to 470,975 persons, which hypothetically hint for a higher incidence of scapular fracture. ${ }^{10}$ Despite that, no reports are currently available from India regarding the prevalence and epidemiology of scapular fractures. Based on this background, we did a pilot project study to plan future research work on the incidence and epidemiology of scapular fractures. The results of the study would help to identify the mass impact of the injury to the trauma victim and laying down the training curriculum for the management of scapular fracture based on the associated injuries.

\begin{abstract}
${ }^{1-4}$ Department of Orthopedics, Postgraduate Institute of Medical Education and Research, Chandigarh, India

Corresponding Author: Devendra K Chouhan, Department of Orthopedics, Postgraduate Institute of Medical Education and Research, Chandigarh, India, Phone: +91 172-2756740, e-mail: drdevnim@gmail.com

How to cite this article: Kumar D, Gupta K, Chouhan DK, et al. Epidemiology of Scapula Fracture at a Level 1 Trauma Center in North India: A Pilot Study. J Postgrad Med Edu Res 2021;55(2):74-76.
\end{abstract}

Source of support: Nil

Conflict of interest: None

\section{Patient Selection and Methods}

It was a cross-sectional study conducted from July 1, 2018, to December 31, 2018, at the level 1 trauma center in the Postgraduate Institute of medical education and research (PGIMER), Chandigarh. The active screening for fracture of the scapula was conducted in all patients presenting to the emergency with polytrauma and shoulder injuries. The patients were screened clinically combined with radiology in conscious patients. However, in unconscious polytrauma patients without any external signs of shoulder injury, only radiological assessment was the main element for screening.

Clinically, the patients with painful shoulder range of motion, swelling, abrasion or bruises around the scapula region, and tenderness around scapula on palpation were evaluated with radiographs for scapula fractures. However, in unconscious polytrauma patients, the chest radiograph was the primary screening tool to identify the fracture of scapula.

All the cases with suspected fracture of the scapula on clinical examination or chest radiograph were advised true anteroposterior 
(AP) shoulder view (Grashey's view) and scapular Y-lateral view. Patients diagnosed with scapula fracture on initial X-ray were taken up for computed tomography (CT) scan with standard axial, coronal, sagittal cuts, and 3D reconstruction views with humerus subtraction. Lateral base offset (LBO), angular deformity between fracture fragments, glenopolar angle (GPA), articular step at glenoid, and displacement of fracture fragments were taken into consideration and accordingly, further management was planned. All intra-articular scapular fractures were classified further according to the Ideberg classification system. ${ }^{11}$

The demographic details, mode, mechanism of injury, associated injury, severity, and fracture pattern of all patients with scapula fracture were recorded. The patients were also evaluated for concomitant injuries.

\section{Statistical Analysis}

This study is mainly descriptive, so data analysis consisted of mean/ median values with maximum and minimum range and standard deviations. The Chi-square test or student's $t$-test were used to analyze the significance of distributions of frequencies by sex and age group.

\section{Results}

Out of total 1,730 patients presented to Advanced Trauma Center, PGIMER, Chandigarh between July 2018 and December 2018, scapular fractures were diagnosed in 44 (2.3\%) patients. Out of all patients diagnosed with scapula fracture, 39 were males and 5 were females. The mean age of the patients was 42.3 years (range $18-67$ years). Also, $63.4 \%$ (28) patients were polytrauma cases out of a total of 44 patients (Flowchart 1).

The majority of patients presented with right-side scapula fracture (27 patients) and left-side scapula was fractured in 15 patients, whereas 2 patients had bilateral injury. The most common mode of injury was RTAs, which was the case in $84 \%$ (37) patients, whereas the rest of the patients had injuries due to fall from height. After the screening of all 1,730 patients presenting to the emergency during the period of the study, 162 patients were clinically suspected of having scapula fracture, out of which 37 patients had scapula fracture on confirmation with radiographs. However, out of all, 57 patients had poor level of consciousness due to associated injuries, and screening for that group of patients was conducted using radiographics only. Total 7 patients had scapular fracture out of 57 patients of the second group (Table 1).

The majority of concomitant injuries included blunt trauma chest, which was diagnosed in 39\% (18) out of all patients with scapula fracture. The clavicle was fractured in $28 \%(13)$, other orthopedic injuries were reported in $24 \%$ (11), head injury in $17.3 \%$

Flowchart 1: Depicting the incidence of scapula fracture

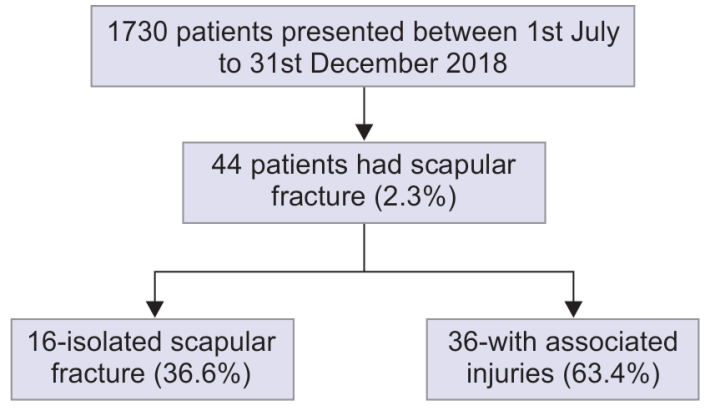

(8), and spine injury in 4\% (2) accounted for other major associated injuries (Table 2). Scapula fracture was associated with brachial plexus injury in 13\% (six), vascular injury in one patient, shoulder dislocation in one patient, and acromioclavicular joint injury in one patient.

The fracture pattern assessment review was done for all 46 fractures in 44 patients (including two patients with bilateral scapula fracture). The scapular body was involved in $41 \%$ (19), glenoid involved in 30\% (14), neck of scapula in 19\% (9), combined fracture in 4 patients, and processes fracture in 2 patients (Table 3 ).

\section{Discussion}

This study was conducted in the level 1 trauma center and tertiary care referral center covering the significant patient load of this region. The reported incidence of scapula fracture in trauma victims was $2.3 \%$ in our series. Previous studies by Court Brown et al. in 2000

Table 1: Demographic details of included patients

\begin{tabular}{ll}
\hline Details & Result \\
\hline $\begin{array}{l}\text { Total number of patients presented } \\
\text { in } 6 \text { months }\end{array}$ & 1,730 \\
$\begin{array}{l}\text { Total patients clinically suspected to } \\
\text { have scapular fracture }\end{array}$ & 162 \\
$\begin{array}{l}\text { Number of patients evaluated radio- } \\
\text { graphically only }\end{array}$ & 57 \\
$\begin{array}{l}\text { Total number of patients with } \\
\text { scapular fracture }\end{array}$ & 44 \\
$\begin{array}{l}\text { Age } \\
\text { Gender } \\
\text { Mode of injury } \\
\text { RSA }\end{array}$ & 42.3 years (18-67) \\
Fall from height & 39 -males, 5-females \\
Side involved & 37 \\
& 7 \\
\hline
\end{tabular}

Table 2: Incidence of associated injuries among scapular fracture patients

\begin{tabular}{ll}
\hline Associated injuries & Number of patients \\
\hline $\begin{array}{l}\text { Chest injuries (rib fractures, pneumomedi- } \\
\text { astinum, pneumothorax, hemothorax) }\end{array}$ & 18 \\
Clavicle fracture & 13 \\
Associated bony injuries (except clavicle & 11 \\
fracture, spine injury) & \\
Head injury & 8 \\
Brachial plexus injury & 6 \\
Spine injury & 2 \\
Vascular injury & 1 \\
Shoulder dislocation & 1 \\
Acromioclavicular joint injury & 1 \\
\hline
\end{tabular}

Table 3: Ratio of fracture patterns among included patients

\begin{tabular}{ll}
\hline Type of fracture pattern & Number of fractures (46) \\
\hline Scapular body & $39 \%(18)$ \\
Glenoid & $28 \%(13)$ \\
Scapular neck & $19.5 \%(9)$ \\
Acromion or coracoid process fracture & $4 \%(2)$ \\
Combined fracture & $8.6 \%(4)$ \\
\hline
\end{tabular}


reported $0.3 \%$ incidence of scapular fracture at their level 1 trauma center. ${ }^{1}$ Brown et al. in 2014 diagnosed scapula fracture using both $\mathrm{X}$-ray and CT scan at level 1 trauma center and incidence measured by them was $1.3 \% .{ }^{12}$ Our finding was corroborative to the increasing trend of scapular fracture over the last two decades. A recent study by Launonen et al. reported increase in annual incidence of scapula fracture from $0.48 \%$ in 1998 to $0.66 \%$ in $2014 .{ }^{13}$ With passing years, a rise in scapula fracture has been observed, which can be explained as an effect of increase in number of RTAs, awareness about fracture of scapula, and primary use of the radiology as a diagnostic tool, specifically in polytrauma and unconscious patients. ${ }^{1,10,12}$ Altered consciousness has been one of the common reasons to miss a scapula fracture and use of radiology as primary tool for diagnosis has made it possible to reduce such incidences. ${ }^{12}$ In our study too, if we had relied solely on clinical examination, we could have missed the scapula fracture in seven patients (15\%), due to the lower conscious level.

Scapula fracture is usually complicated by associated severe injuries to the vital organs. In our study, $63.4 \%$ of the patients had associated injuries, while the rest of the patients had isolated scapula fracture. A retrospective analysis by Ada et al. on 113 scapula fracture patients depicted that $96 \%$ of patients had associated injuries, where chest injury was the major insult (rib fracture in 37\%, hemopneumothorax in $29 \%$, pulmonary contusion in $8 \%$ ). ${ }^{3}$ Other injuries reported were head injury in $34 \%$, clavicle fracture in $25 \%$ patients, brachial plexus injury in $3.5 \%$ patients, and subclavian artery injury in $1 \%$ patient. ${ }^{3}$ In a study by Brown et al. on 144 patients with scapula fracture, $58(40.2 \%)$ reported with associated pneumothorax, 27 (18\%) had hemothorax, and 26 (18\%) with clavicle fracture. ${ }^{12}$ Data reviewed by Launonen et al. depicted concomitant injuries in $55 \%$ of patients comprised of blunt trauma chest in $23.4 \%$, clavicle fracture in $16.5 \%$, and cervical spine or head injury in $6.9 \%$ of total patients. ${ }^{13}$ Associated injuries in scapular fracture patients lead to increased morbidity, higher injury severity scores, which limit the management protocols. In our study, chest injuries (rib fractures, pneumomediastinum, pneumothorax, hemothorax) were reported in $39 \%$ (18) patients, clavicle fractures in $28 \%$ (13), other orthopedic injuries in $24 \%$ (11), head injury in $17.3 \%$ (8), brachial plexus injury in $13 \%(6)$, and spine injury in $4 \%$ (2) of patients. Incidence of the serious associated injury in cases with scapula fracture was found to be much less than previous reports.

Similar to demographic figures in other orthopedic injuries, higher presentation in males was seen in our study. Increased incidence among males (M:F ratio-8:1) might be attributed to the more active status of males in the community making them susceptible to accidents. The most common mode of injury in the previous study is RTA, followed by fall from height. ${ }^{12}$ Age of affected patients range from 18 to 67 years (mean age- 42.3 years) in contrast to 5 to 75 years (mean age -25.9 years) in the study by Ada et al. and 16 to 85 years (mean age -43.6 years) in the study by Courtlyn Brown et al. ${ }^{3,12}$

Fracture of the scapular body was the commonest pattern in our series, which is comparable to findings of the Ada et al. ${ }^{3}$ However, the incidence of the intra-articular fracture of glenoid was relatively more frequent and comparable to reports of Ideberg et al. and Schandelmaier et al. ${ }^{14,15}$ It is important to understand that intra-articular fracture involving the glenoid fracture requires surgical intervention more often than the extra-articular fracture of the scapula. This finding could be significant in identifying the future area of research at our center.
The limitation of this study was the small sample size; however, this was a pilot study designed to find the relevance of doing further research in our setup.

\section{Clinical Significance}

The results of this study have raised the awareness that the incidence of scapula fracture is rising in comparison to what was thought previously.

\section{Conclusion}

Our study mandates the need for more dedicated screening methodology at busy trauma center, which can reduce the chances of missed scapula fracture. Moreover, further research would enable the identification of more frequent fracture patterns and specific areas of research to our setting.

\section{References}

1. Court-Brown CM, Caesar B. Epidemiology of adult fractures: a review. Injury 2006;37(8):691-697. DOI: 10.1016/j.injury.2006.04.130.

2. Tuček M, Bartoníček J, Klika D, et al. Epidemiology of scapular fractures. Acta-Orthop Belg 2017;83:8-15.

3. Ada JR, Miller ME. Scapular fractures. analysis of 113 cases. Clin Orthop Relat Res 1991;269:174-180.

4. Armstrong $C P$, Van der Spuy J. The fractured scapula: importance and management based on a series of 62 patients. Injury 1984;15(5):324329. DOI: 10.1016/0020-1383(84)90056-1.

5. Thompson DA, Flynn TC, Miller PW, et al. The significance of scapular fractures. J Trauma 1985;25(10):974-997. DOI: 10.1097/00005373198510000-00008.

6. Cole PA, Gauger EM, Schroder LK. Management of scapular fractures. J Am Acad Orthop Surg 2012;20(3):130-141. DOI: 10.5435/JAAOS-2003-130.

7. Goss TP. Fractures of the glenoid cavity. J Bone Joint Surg 1992;74(2):299-305. DOI: 10.2106/00004623-199274020-00019.

8. Anavian J, Gauger EM, Schroder LK, et al. Surgical and functional outcomes after operative management of complex and displaced intra-articular glenoid fractures. J Bone Joint Surg Am 2012;94(7):645653. DOI: 10.2106/JBJS.J.00896.

9. Cole PA, Gauger EM, Herrera DA, et al. Radiographic follow-up of 84 operatively treated scapula neck and body fractures. Injury 2012;43(3):327-333. DOI: 10.1016/j.injury.2011.09.029.

10. Transport Research Wing. Ministry of road transport and highways. road accidents in India 2017. New Delhi: Government of India, Ministry of road transport \& highways transport research wing, [cited July, 2018]. Available from: https://morth.nic.in/sites/default/files/ Road_Accidents_in_India_2017.pdf.

11. Ideberg R. Fractures of the scapula involving the glenoid fossa Bateman JE, Welsh RP, ed. Surgery of the shoulder. Philadelphia: Decker; 1984. pp. 63-66.

12. Brown C, Elmobdy K, Raja AS, et al. Scapular fractures in the panscan era. Acad Emerg Med 2018;25(7):738-743. DOI: 10.1111/acem. 13377.

13. Launonen AP, Laitinen MK, Sumrein BO, et al. Trends in scapular fractures: a nationwide 17-year study in Finland. JSES Int 2019;4(1):59-62. Published 2019 20th December 10.1016/j.jses.2019. 10.111.

14. Ideberg R, Grevsten S, Larsson S. Epidemiology of scapular fractures. incidence and classification of 338 fractures. Acta Orthop Scand 1995;66(5):395-397. DOI: 10.3109/17453679508995571.

15. Schandelmaier $P$, Blauth $M$, Schneider $C$, et al. Fractures of the glenoid treated by operation. A 5- to 23-year follow-up of 22 cases. J Bone Joint Surg 2002;84-B(2):173-177. DOI: 10.1302/0301620X.84B2.0840173 